\title{
Learning theory through doing: Applying design studio methods in the construction of an academic argument
}

Mike McAuley and Mark Roxburgh, University of Newcastle, Australia

\begin{abstract}
This paper presents the outcomes of an action research inquiry that set out to enhance first year visual communication student learning of design theory and history through the incorporation of creative practice methods commonly used in practical design studio environments. As educators of both design theory and practice, our previous observations of how novice design students engaged with theory, compared to how they engaged with practice, led us to the decision that change was required to facilitate deeper understanding of theoretical discourse through the incorporation of creative practice methods. That was our 'call to action'. The methods, described in the article as interventions, were introduced to support the critical and analytical thinking necessary to engage with theoretical discourse. They can also be thought of as learning strategies incorporated to enhance student learning and involved creative thinking exercises, visualization techniques, collaboration and audience presentation. Our findings demonstrate that student learning of design theory and history can be enhanced when creative practice methods are employed within a critical studies context and that discourse in design education is no longer the exclusive domain of the written word.
\end{abstract}




\section{Keywords}

action research

learning strategies

creative methods of enquiry

design theory and history 


\section{Introduction}

Cross argues that the discipline of design needs 'to develop domain-independent approaches to theory and research' because ‘there are forms of knowledge special to the awareness and ability of a designer, independent of the different professional domains of design practice’ (2001: 4). Further to this he adds, 'we must concentrate on the "designerly” ways of knowing, thinking and acting' (Cross 2001: 5). In a similar vein Strickler argues that the development of visual communication design as an academic discipline will only occur when there is an 'empirical bridge between theory and practice' (1999: 38). Constructing this bridge is no easy task because the kind of students drawn to design are more often than not visually articulate and practically oriented in their approach to learning. Theory and practice conventionally draw on different modes of thinking and doing. Theoretical enquiry can be described as an activity that uses explicit knowledge and deductive logic while studio practice in comparison draws on tacit knowledge and inductive/abductive reasoning (Lawson 1980). Although seen as being different ways of thinking there is literature exploring the rich potential in their combined use to enhance student learning of theory in tertiary creative art and design schools. One stream of that literature provides case study evidence of the effectiveness of using creative techniques that parallel the creative process but the evidence typically provided is the researcher's analysis of the processes and outcomes themselves with generalizations made about improved students learning. Whilst this research has been invaluable in contributing to the development of theoretical studies within art and design programmes there is considerably less published literature that analyses student feedback on, or experiences of, these techniques and their efficacy. In this article we will demonstrate, through the analysis of student interviews, that the methods of thinking and doing 
design can be effectively combined with the methods of thinking and doing theory to enhance student understanding of complex theoretical material.

With this in mind we set out, at the University of Newcastle, to introduce methods of practice common to our design studio classes into our first year design theory and history course DESN $1002^{1}$ with a view to examining their effectiveness on student learning. In the previous semester we had introduced similar methods into the preceding theory course DESN $1001^{2}$ but the emphasis of our analysis of student learning in that was centred on the collaborative nature of learning theory through group work, also typical of studio classes but not common in theory courses (McAuley and Roxburgh 2015). We also introduced research presentations in DESN1001 and noted that students were very comfortable with discussing their research findings through digital visual media support via large screens set up in the theory classes. As student feedback on the value of collaboration and visual presentations was very positive we decided to develop this further in our second semester design theory and history course, DESN 1002, with our analysis of student learning focused on the role of the visual presentations. Within the methodological structure of action research, characterized as being based around an iterative, incremental and cyclical research design, we describe semester one's enquiry as cycle one and the semester two enquiry as cycle two. We will concentrate on describing cycle two in this article and will, when relevant refer to cycle one. This relates to one of the important guiding principles of action research, that knowledge development is cumulative through cyclical, incremental development.

\section{Methodology and research design}


Action research in its broadest sense is concerned with bringing change to an identified situation requiring improvement and, through the incorporation of rigorous methods of enquiry, it can also result in new understanding (Hopkins 1985). It is this second component, requiring rigour of enquiry that differentiates it from common classroom practice, as teachers often seek to improve their teaching by the incorporation of interventions (McNiff and Whitehead 2006). A fundamental principle of action research is that the researcher is at the centre of the enquiry, not a detached observer (Dick 1993; McNiff and Whitehead 2006). It has the combined goals of improving student learning while also attempting to improve teaching practice, initially that of the practitioner engaged in the research. The research component makes visible what enhanced learning took place in such a way that its findings can be shared by others. As such, action research sits within the domain of social science. Having said that, it is not a traditional form of social science that McNiff and Whitehead describe as being ‘outside a situation’ (2006: 8). They say 'Action researchers, however are insider researchers. They see themselves as part of the situation they are investigating' (2006). Trigwell (2004: 13) talks of 'pedagogic resonance' to describe the value of a teacher's knowledge but suggests that for personal knowledge of teaching to become scholarship it must be made verifiable through a structured and methodologically rigorous approach. Through a looping process initially developed by Lewin ([1946] 1948) the cyclical nature of action research is described by Kemmis and McTaggart (1992: 10) as plan-act-observereflect. Morrison (1995) says it has similar properties to Schön’s (1987) 'reflection in action'. Schön (1983) introduced the term reflective practice as he sought to develop a way of looking at an epistemology of practice based on examining what practitioners do. He argues that reflection-in action is 'susceptible to a kind of rigor 
that is both like and unlike the rigor of scholarly work and controlled experimentation' (1983: xi). Swann (2002) draws our attention to the similarities of action research to the design process that he describes as problem-analysis-synthesisexecute-production-evaluation. Swann suggests that the cyclical, iterative similarities between design process and action research are, 'very striking' (2002: 56). Another notable aspect of action research is its symbiotic relationship between researcher and participant. Giddens (1987: 20) talks of a 'double hermeneutic' to describe this twoway relationship between the researcher and the participant, referring to how meaning and understanding is a negotiation between two parties. This is unlike a 'single hermeneutic' approach, where understanding is essentially one-way (1987), as in, for example, a scientist studying properties of a mineral. This also relates to what Weber (1947 cited in Clark 1997: 34) describes as verstehen. Verstehen can be broadly translated as meaning empathetic understanding as a consequence of familiarity with the subject of study. This relates to insider knowledge as opposed to outsider knowledge that is more common in traditional social science research. Both researchers involved in this study are designers and design academics. This supports Cross’ (2001) domain independent position.

The study can also be described as a naturalistic enquiry. Naturalistic enquiries focus on real world situations that unfold naturally, they are non-manipulative or controlling and open to what emerges (Patton 2002). The unifying feature of naturalistic enquiry is that it must take place within a real world setting, a setting with which participants are familiar. We also position this study as a situated learning enquiry. According to Clancey, 'Situated learning is the study of how human knowledge develops in the course of activity, and especially how people create and interpret descriptions (representations) of what they are doing' (1995: 49). 
While there are structural variations to Lewin ([1946] 1948) and Kemmis and McTaggart’s (1992) plan, act, observe, reflect, model, such as McNiff and Whitehead's (2006) observe, reflect, act, evaluate, modify, move in new direction, the research design of this study followed the original model established by Lewin. Our 'plan' for cycle two was based on our observations and reflection that the collaboration intervention in the first semester course DESN 1001 had been successful and that students appeared to be very keen to further explore collaboration as well as incorporate more visual strategies to support the development of theoretical positions relevant to their study of design theory. Cycle one's plan was based on observations that visual communication design students were less engaged and performed less well in theory classes which required an almost exclusively written text approach to critical discourse through the writing of essays. So, in cycle two the planned action was to further develop student learning strategies based on creative practice methods they were familiar with from studio classes, specifically in this instance audio-visual presentations, and bring them into their theory class.

\section{Literature}

The emergent literature exploring the problems creative art and design students have in reconciling the conventions of academic analysis and writing, which privileges explicit knowledge and deductive logic, with their predilection for learning by doing and the use of intuition can be characterized as having two main thematics. The first thematic maps the variety of personal, cultural, historical or institutional contexts and causes that have lead to these problems arising in the first place (Candlin 2000; Elkins 2004; Hockey 2007; Kill 2006; Melles and Lockheart 2012; Wood 1998). This 
literature tends towards a theoretical and empirical survey of the history, or the present state of the problem, and is invaluable for doing so but it does not tend to explore specific strategies for dealing with it. The second thematic sees these difficulties as being a kind of clash of cultures arising from conservative institutional academic requirements and norms versus the lack of creative art and design student ability or interest in those norms. Literature exploring this thematic tends to outline the extent of the problem in general terms and/or articulates strategies for overcoming or 'solving’ it (Bhagat and O’Neill 2009; Blackler 2014; Collinson 2005; Edwards 2004; Grow 1994; Hockey 2007; Lyon 2009; Roxburgh and Bremner 2001; Roxburgh and Sweetapple 2007).

Regardless of the orientation of the literature - survey of the problem versus solving the problem - its unifying theme is the frustration creative art and design students feel towards institutional requirements to engage with conventional academic analysis. Overwhelmingly the literature indicates that tertiary creative art and design students are poorly equipped with the kind of analytical thinking skills required for conventional academic reading and writing but are well equipped with the intuitive thinking skills required to create art or design outcomes (Apps and Mamchur 2009). The literature often argues that these intuitive thinking skills are related to the preference creative art and design students have for visual approaches to learning. Collinson describes the learning style of such students as connecting the emotional investment they have with what they create to the intuitive manner in which they bring it into being (2005: 716-17). Lockheart et al. (2004: 97) talk about these learning styles as being typical of visual-spatial learners who Yee (2012: 471) notes 'tend to think in pictures rather than words'. Irwin (2003: 63) in turn refers to this style of learning as a form of aesthetic knowing 'that values sensory awareness, 
perceptual acuity, attunement, wonderment, novelty, and emergence'. This of course points to the tacit dimension of knowledge that McCannon notes is a prized part of studio learning (2011: 133). Finally Blackler (2014), Edwards and Woolf (2007: 55) and Grow (1994) all use the term visual thinking to denote the visual approach to learning. In spite of the different emphases these characterizations have what they share is a sense that learning that occurs through a combination of looking and doing is privileged over learning that occurs through reading and listening. Significantly learning through looking and doing map on to two of Gardner’s (1985) seven intelligences: looking leverages visual-spatial intelligence and doing leverages bodily kinaesthetic intelligence.

Much of the available literature dealing with the tension between kinaesthetic styles of learning, and the more analytical styles of conventional academic discourse, concentrates on the description and efficacy of techniques used to assist creative art and design students develop appropriate writing and analytical skills. Commonly, this literature reports on the success of taking a student centred approach, using their studio practice as the starting point for research and/or writing, and using or developing a variety of writing genres that better parallel the creative process.

Roxburgh and Bremner (2001) discuss the use of a variety of visual techniques including mapping, audio-visual presentations and multimedia essays in design theory courses they ran in Singapore from 1998 until 2000 that draw 'upon the students configurational skills' in design a way that develops 'knowledge through design and not just about it' (2001: 71). However the analysis of the impact of these techniques upon student learning is largely absent as the article takes a macro view of the curriculum philosophy and structure of a degree top-up programme. Preston and 
Thomassen focus on the use of the 'four exemplar media' (2010: 47) they get students to use to develop their concepts as they move towards writing in a process they call 'designing writing' (2010: 45). These techniques 'have been prioritized on their level of operability in the act of design, and as a way to communicate design thinking and strategies' (Preston and Thomassen 2010: 45) and thus leverage students visualspatial learning styles. Whilst the use of these media have strong parallels with the interventions we examine in this article their research focuses on the role of the media, in the form of the artefacts produced, through the learning process rather than on ascertaining from the students themselves if the methods were efficacious. Apps and Mamchur (2009) take a case study approach of post-graduate creative art students struggling with the demands of academic writing. While their research clearly identifies the themes common to the literature, like Preston and Thomassen (2010) the focus is on the process and outcomes with no evidence drawn from the students themselves.

Kill, on the other hand, draws upon student interviews but the focus of the research is centred on 'student conceptions of writing' (2006: 314) rather than upon the efficacy of any learning strategies to improve that experience. Likewise Lyon (2009) draws upon interviews with lecturers and students but again the research is focused on identifying the parameters of the problem itself and the experience of participants in relation to it, rather than exploring strategies for dealing with it. Whilst Edwards (2004) takes a case study approach in examining the use of visual techniques in thesis writing, like Apps and Mamchur (2009) and Preston and Thomassen (2010) she focuses primarily on the processes and outcomes. However there is a small section towards the end of the article that draws upon direct evidence from student feedback that clearly demonstrates the effectiveness of these approaches. 
Jones analyses interviews with MA students in exploring the efficacy of the technique of 'bisociation within-keyword mapping' (2007: 19) used in the development of their written design proposal. These techniques draw upon Buzan’s mind mapping methods that are commonly used in design concept development (see e.g. Kokotovich 2008; Roxburgh and Cox 2016). Although Jones' research demonstrates the techniques helped students in developing their concepts and their writing skills the purpose of the exercise was to develop a critical reflective studio practice and as such does not focus so much on the content typically found in design theory subjects.

'In examining the theory practice synthesis’ Camino (2010) does draw on empirical research into the learning experiences of honours students however, the focus of the article is on the role of theory, through the guise of reflective journal writing, in providing 'direct support to students' own practice'. Whilst the research does indicate the efficacy of this approach it looks at theory driving a deeper understanding of practice whereas our approach is using practice to develop a deeper understanding of theory.

Cattaneo (2013) explores the 'patchwork' model where students write a number of shorter pieces of text, as opposed to a long form essay, that are then shared and critiqued with their peers prior to submission for assessment. This leveraged 'the same social dimension as the studio practice model of group working, discussion and critique' to develop honours students' writing (Cattaneo 2013: 171). In addition students had to produce a poster to explore a key concept. Cattaneo’s analysis of students self-reporting and questionnaires concluded that this studio approach to learning theory leads to 'an increased confidence in the expression of their own opinions' (2013: 184) in both oral and written form. Similarly Roxburgh and 
Sweetapple (2007) provide case study examples of visual mapping techniques used in design theory courses coupled with the analysis of reasonably detailed student feedback on their experiences of this approach.

Lockheart (2010) examines written student responses to a Ph.D. writing workshop that drew upon Jones (2007) bisociation technique to develop a collaborative piece of writing to help develop their writing skills. The designerly approach this entailed, both in the form of the techniques and the collaborative nature of the workshop, was well received by the participants helping them grow in confidence in their writing and contributing to a deeper insight into their research. Again this feedback demonstrates the effectiveness of the designerly approach to teaching theory.

Mansell is also concerned with the relationship between academic conventions and creative practice at the Ph.D. level and aims for 'a blending of the creative and critical discourse in order to materialize the critical incident in language, and thereby crystallizing it for the purposes of reflection of a non-traditional type' in the supervision of a 'traditional Ph.D. thesis in the humanities' (2013: 300). The student feedback attests to the effectiveness of this approach in the written feedback Mansell analyses but the sample pool of data is from one student only.

Reeve sets out to overcome 'the studio/theory divide' and make 'writing more relevant' (2014: 273) using feedback from students to evaluate the success of her approach. She argues that 'Art \& Design students will engage more fully and experience deeper learning if theory assignments are taught in a way that echoes learning and teaching in the studio' (2014: 268). Many of the techniques she cites are similar to those outlined in our own approach and her conclusion that 'offering a multimodal, creative approach to writing and research can help to overcome student 
barriers to engagement and learning by offering a less intimidating and more inclusive learning experience' (Reeve 2014: 279) parallels own on research. However, it is not clear how the reasonably extensive ‘feedback from student workshops’ (Reeve 2014: 268) cited and analysed was captured.

The literature outlined above clearly points to a shift in the teaching of academic reading and writing in tertiary art and design schools, away from more conventional approaches towards more creative approaches, that leverage students visual and kinaesthetic aptitude. In the field of constructivist learning theory this is known as kinaesthetic or experiential learning, where learning is more profound when connected to the concrete and embodied experiences of the learner (Kolb 1984). Ramsden (2003: 39-61) argues that to facilitate deep learning experiences the learning styles and predispositions of students must be accommodated. This theoretical backdrop as well as our prior experience of teaching theory and history led to the learning interventions we incorporated into our teaching.

The majority of the published literature on this topic is based upon the observations and experiences of the authors and tends to either describe the problem or report on case study work that offers alternative approaches. Whilst this research has been foundational in mapping out a trajectory for where the teaching of theory in creative art and design schools has been and is heading there is considerably less literature that directly evaluates the student learning experience, as captured in interviews or questionnaires, in taking these approaches. It is the intention of this article to build upon and contribute to the scant work that directly analyses data collected from students about their learning experiences in such a context. The questionnaire replies reviewed in this article support the views expressed in the literature that visual, 
kinaesthetic and collaborative methods of engaging with critical discourse suit visual communication design students and provide concrete evidence of the effectiveness of this approach.

\section{Learning strategies and interventions}

Essentially our interventions were based around learning strategies. Learning strategies can be described as behaviours and thoughts a learner engages in during learning that are aimed at creating and constructing meaning and knowledge. Learners are, to use Mayer’s (1996: 364) constructivist definition, 'sense makers'. Learning strategies are, within Mayer's framework, sense making processes used when a learner 'actively tries to build a coherent and meaningful representation of the presented material' (1996). To facilitate student understanding of the historical dimensions of design history within a broader social context, our interventions included the following:

- Students had to work in groups of three or four (as is common in studio practice)

- Students had to co-create and present a visual and oral presentation on a topic relevant to design history (in contrast to writing an essay).

To ensure academic rigour, the visual presentations had to include throughout, cited references to the literature pertinent to their topic. The assignment brief asked students to choose a key moment in visual communication design history and discuss its significance within a social and historical context. The students were also asked to provide evidence to support their position.

\section{Research data}


In keeping the literature, outlined above, examples of student outcomes form part of the data analysed to gauge the effectiveness of the learning interventions developed. In this particular instance content analysis was carried out. However, unlike much of that literature our main source of data for gauging the experiences of the students themselves was questionnaires filled out in class. To avoid ethical issues no fieldwork or formal research took place during teaching time and we kept our roles as teachers and researchers separate. The questionnaires were voluntary and anonymous. In cycle one, 49 students handed in the questionnaire and in cycle two we received 43 responses. Both cycles, based on the semester one and two courses involved the same student cohort. Knowledge gained from both cycles is therefore cumulative. The data are also homogenous in that all students involved had similar expertise with design and theory.

\section{Cycle one}

Before we discuss our findings from cycle two we would like to briefly highlight a key finding of the first cycle questionnaire that focused on the role of collaboration in assisting learning.

\section{Q.1. Please describe what role working collaboratively with your peers played in} assisting your own personal understanding and ability to articulate what design is.

The most commonly recurring adjective that repeatedly appeared in the questionnaire responses was helped (15) with linked variations such as helpful (5), helping (2), help (1.) Other associated words used included useful, broadened, good, allowed, allows, assisted, enabled, liked, engaged. The overall pattern that emerged from question 1, 
as regards why collaboration assisted student learning was that the experience allowed students to hear different perspectives about the texts they all had to read:

They brought personal introspects and thought paths into my perspective which I may not have thought of myself

It provided different insight/perspectives on design

The feedback on cycle one prepared us for cycle two which in addition to exploring collaboration also looked at the role of using visual, co-creative methods to support group presentations on key figures, movements and moments in design history. These are the interventions incorporated into the design history course that we argue enhanced student engagement and facilitated deeper understanding and knowledge generation.

\section{Analysis, cycle two}

Forty three students handed in cycle two's questionnaire. The first two questions related to working visually and orally in the production of a group presentation.

Q 1. You have been asked to do a visual and oral presentation of your chosen topic. From your own experience please describe how this approach has assisted you develop critical and analytical understanding of design within a historical context, i.e. an academic understanding.

The overall pattern to emerge from student comments was that the visual and oral approach helped consolidate personal understanding of their topics and that this approach was easier than conventional writing. A number of students said that by having to explain things verbally and visually to a real audience they were able to 
develop a better understanding of their topic. The data holistically presented a pattern that suggests that the physical act of presenting to a live audience of peers and supervisor had a kinaesthetic element, which the students valued. The following are representative comments from students:

By 'teaching' we are forced to understand better ourselves.

As I am having to talk and inform people, I find I learn more and develop a better understanding. I find myself going to much further lengths to explain what I have learned.

Editing the visuals really makes the whole thing stick in your head

The following full unabridged excerpt encapsulates the types of responses students made to this question:

As the presentation approach is more visual and less focused on academic/critical writing, I think this approach has enhanced the learning in understanding historical context. I was more engaged in wanting to learn and research the chosen topic. You are able to view things differently and interpret the information in your own creative and visual way.

Question 1 related to the presentation students gave. Question 2 relates to the first question but is more interested in finding out how the visual and creative process facilitated each student's personal learning.

Q. 2. What role has working visually and creatively played in assisting your own personal learning and approach? 
The overall pattern to emerge was that a visual and creative approach was helpful. Students used a diverse array of terms to describe this. The most common were helped (11) helpful (3) helps (2). Other terms included: easier to understand, more enjoyable, played a major part, greatly assisted, more understandable, allows me to connect, engages my mind more.

Thinking in terms of images and visuals makes us simplify and process information differently

I get a better idea of things when I can visualize them so I find working with resources like we have to be very helpful

Working visually and creatively has played a huge part in my personal learning.

I am a visual and hands on learner so this has helped me in grasping many difficult concepts.

The visuals and being creative with them really hammered the academic into my head. I learn much more if visuals are heavily involved.

\section{Visual presentations and the role of audience}

In total there were twenty group presentations with 69 students involved. Topics ranged from discussions of the Bauhaus, Dada, Art Nouveau, advertising, avant-garde art, animation and so forth. Each talk also focused on individuals who had played an important role in their movement. Students were encouraged to place their chosen movement within a historical timeline and conclude with a discussion of the movement's legacy in contemporary times. 
The basic academic premis of ‘claim' followed by 'evidence' was enforced and students were encouraged to incorporate quotes that helped contextualize their topic and refer to the academic literature where appropriate. Students were told to speak to the quotes and explain their significance. Students were also asked to consider their presentation title as providing a contextual overview of the presentation. Kintsch (1998) describe titles as macropropositions, a short selection of words that capture the 'gist' of an idea or text. Another important consideration was the chosen aesthetic for the presentation and how it could also be used to provide context, something that would not be expected in a written essay.

The presentations were fifteen to twenty minutes long and each student had responsibility for a section. The presentation slides were, on the whole, uncluttered with a combination of images and text. Each presentation included quotes from the literature and students, on the whole discussed the relevance of the quotes as would be expected in an essay structure.

Figure 1: Four images from a presentation. Total number of slides in presentation was 24.

An important aspect of the presentations that students enjoyed was the opportunity to engage directly with their audience of peers and ask questions. This allowed for the communication to be a two way dialogue rather than simply a transference of viewpoint from presenter to audience. Some students mentioned the value of this in their feedback sheets. This is common in studio environments where the critique is of great value, but our prior experience of teaching theory is that the relationship between the student as author and the audience is a detached one. We had not previously considered a critique of theory and the value of the audience. The role of 
the audience became one of the most significant factors in enhanced student learning. It was also an important discovery for us as educators.

Clark (2004: 14) says that the basis for all communicative acts is meaning and that it is created through 'a complex interplay of codes or conventions of which we are normally unaware'. He also describes it as a participatory act between speaker and addressee. Building on the work of Austin (1962) and Searle (1969), Clark further describes this joint action as an illocutory act (the speaker's act of explanation) and an illocutionary effect (the addressee’s understanding) (2004: 133, 134). In an essay, it can be argued that the relationship between speaker and addressee is detached. Certainly for an undergraduate design student, the only audience they are aware of when they write an essay, is their lecturer. In a scholarly visual and oral presentation there is room for dialogue. Tyler says 'audience considerations are integral components of the process of visual communication' (1995: 104). As Mayer (1996) discussed earlier, students are sense makers and visual communication design students are familiar and comfortable working in the visual domain. On the whole, the literature supports the view that the learning preferences of visual communication design students are oriented towards the visual-spatial. We believe this approach helped them make sense of the historical and theoretical material they were dealing with.

Figure 2: Image on left shown first and audience asked to identify the isotypes.

Figure 3: Demonstrates how students were able to demonstrate the power of isotypes by asking the audience to identify each image. This audience interaction enforced the idea that isotypes are powerful and memorable mechanisms of communication. 
Presentations allowed students to demonstrate how theory works in practice. In Figure 3 a student group whose research focus was Otto Neurath’s Isotype language discussed Saussure's famous quote 'Everything is based on relations'. They used the contemporary app icon 'Snapchat' to discuss how icons work. They were able to do this by showing a shape minus some of its recognizable features. The audience was still able to recognize the app. The group then presented a semiotic analysis of the app using Saussurian terminology such as signified/signifier. So, as such they were explaining theory by using an example of their choosing and, by taking advantage of the sequential nature of slide presentation, they were able to visually demonstrate and explain ideas that may have been more difficult in an essay structure.

All student presentations were based on demonstrating the significance of various design movements or individuals whose work has had a significant impact on the development of design as a discipline. This was to be placed within a historical context. It allowed students to make links between past events in design history and understand their significance to current design practice.

\section{Plan, act, observe, reflect: Conclusion}

This study set out to overcome a problem and test the efficacy of the solution by examining student experience of it. The problem, as observed from previous experience teaching theory and history to visual communication design students, was that many students were not engaging with theory at a deep intrinsic level. Many students wrote essays where there appeared to be little real engagement with the topic and that they were motivated more by the extrinsic demands of passing a course than actual fascination with the topic of study. In addition to this, observations also suggested that a high proportion of students were not necessarily seeing the value of 
theory, or the legacy of the history of design, to their developing understanding of their own design practice. In contrast to this, visual communication design students thrive in studio environments where collaboration and immersion in visual methods of working are the norm. By bringing these methods into the design theory and history classes we believe we have enhanced learning by enabling students to make sense of things through the utilization of 'designerly ways of knowing'. This however, is not simply a view formed by us as researchers and educators based upon an analysis of the outcomes produced by students or our observations of them in class. Rather, the evidence that these interventions are effective is borne out by the data drawn from the students themselves via the questionnaires.

\section{References}

Apps, L. and Mamchur, C. (2009), 'Artful language: Academic writing for the art student', The International Journal of Art and Design Education, 28:3, pp. 269-78.

Austin, J. L. (1962). How to do things with words. Oxford University Press.

Blackler, A. (2014), 'Using a visually-based assignment to reinforce and assess design history knowledge and understanding', Design Research Society Conference Proceedings, Umea: DRS. 
Camino, M. (2010), 'An examination of the Journal used as a vehicle to bring about a synthesis between theory and practice in Art and Design higher education', Journal of Writing in Creative Practice, 3:3, pp. 317-40.

Cattaneo, J. (2013), “The “Creative Arts Patchwork Project”: An alternative to the academic essay', Journal of Writing in Creative Practice, 6:2, pp. 169-86.

Clancey, W. J. (1995), ‘A tutorial on situated learning’, in J. Self (ed.), Proceedings of the International Conference on Computers and Education, Charlttesville, VA: AACE, pp. 49-70.

Clark, H. (2004, Using language. Cambridge: Cambridge University Press.

Clark, J. (1997), Educational Research: Philosophy, Politics, Ethics, Palmerston North: ERDC Press.

Collinson, J. A. (2005), 'Artistry and analysis: Student experiences of UK practicebased doctorates in art and design', International Journal of Qualitative Studies in Education, 18:6, pp. 713-28.

Cross, N. (2001), ‘Designerly ways of knowing: Design discipline versus design science’, Design Issues, 17:3, pp. 49-55. 
Dick, B. (1993), 'You want to do an action research thesis?',

http://www.aral.com.au/resources/arthesis.html. Accessed 4 November 2015.

Edwards, H. and Woolf, N. (2007), 'Design research by practice: Modes of writing in a recent PhD from the RCA', Journal of Writing in Creative Practice, 1:1, pp. 53-67.

Gardner, H. (1985), Frames of Mind: The Theory of Multiple Intelligences, New York: McGraw-Hill.

Giddens, A. (1987), Social Theory and Modern Sociology, Cambridge: Polity Press.

Hopkins, D. (1985), A Teacher’s Guide to Classroom Research, Milton Keyes: Open University Press.

Kemmis, S. and McTaggart, R. (eds) (1992), The Action Research Planner, 3rd ed., Geelong, Victoria: Deakin University Press.

Kintsch, W. (1998), Comprehension, a Paradigm for Cognition, Cambridge:

Cambridge University Press. 
Kokotovich, V. (2008), 'Problem analysis and thinking tools: An empirical study of non-hierarchical mind mapping', Design Studies, 29:1, pp. 49-69.

Kolb, D. A. (1984), Experiential Learning: Experience as the Source of Learning and Development, New Jersey: Prentice Hall.

Lawson, B. (1980), How Designers Think, London: Architectural Press Ltd.

Lewin, K. (ed,) ([1946] 1948), ‘Action research and minority problems’, in Resolving Social Conflicts, New York: Harper \& Row, pp. 201-16.

Lockheart, J. (2010), 'How can we use writing as a tool for collaboration across disciplines at Ph.D. level?: Co-writing fictional versions of the truth about someone else', Journal of Writing in Creative Practice, 3:3, pp. 299-315.

Lockheart, J. et al. (2004), 'Writing purposefully in art and design (Writing PAD)', Art Design and Communication in Higher Education, 3:2, pp. 89-102. 
Mansell, L. (2013), 'Wing-words and frameways: Materializing the critical incident through poetic enquiry and reflective practice in doctoral supervision', Journal of Writing in Creative Practice, 6:2, pp. 299-321.

Mayer, R. E. (1996), ‘Learning strategies for making sense out of expository text: The SOI model for guiding three cognitive processes in knowledge construction', Educational Psychology Review, 8:4, pp. 357-71.

McAuley, M. and Roxburgh, M. (2015), 'Designerly ways of learning theory:

Combining creative and scholarly methods of inquiry', in L. Collina, Galluzo L. and A. Meroni (eds), Proceedings of The Virtuous Circle Design Culture and Experimentation, Cumulus Conference, June 3-7, Milan, pp. 1333-44.

McCannon, D. (2011), 'Towards the hybrid essay: The visual essay project', Journal of Writing in Creative Practice, 4:2, pp. 131-40.

McNiff, J. and Whitehead, J. (2006), All you need to know about Action Research, London: Sage Publications.

Patton, M. Q. (2002), Qualitative Research \& Evaluation Methods, 3rd ed., Thousand Oaks: Sage Publications. 
Ramsden, P. (2003), Learning to Teach in Higher Education, 2nd ed., London and New York: Routledge Falmer.

Reeve, J. (2014), 'How can adopting the materials and environment of the studio engage Art \& Design students more deeply with research and writing? An investigation into the Reframing Research technique', Journal of Writing in Creative Practice, 7:2, pp. 267-81.

Roxburgh, M. W. D. and Cox, S. (2016), 'Visualisation and the service sector: Why visual communication design is central to designing the immaterial', Studies in Material Thinking, 15, pp. 1-19.

Schön, D. A. (1983), The Reflective Practitioner: How Professionals Think in Action, Basic Books.

Searle, J. R. (1969). Speech Acts. Cambridge University Press.

Strickler, Z. (1999). Methods in experimental design research. Design Issues, Vol. 15, no 2, Design research (Summer, 1999), pp. 27-39. MIT Press.

Swann, C. (2002), 'Action research and the practice of design’, Design Issues, 18:2, pp. 49-61.

Trigwell, K. (2004), ‘The scholarship of teaching: What is it, and does it matter?’, in A. Davies (ed.), Proceedings of the CLTAD Enhancing Curricula: Exploring Effective 
Practices in Art, Design and Communication in Higher Education, London: The Centre for Learning and Teaching in Art and Design, pp. 13-27.

Tyler, A. C. (1995), 'Shaping belief: The role of audience in visual communication design', in Margolin and Buchanan (eds), The Idea of Design, Cambridge: The MIT Press, pp. 104-12.

Yee, J. (2012), 'Implications for research training and examination for design PhDs', in R. Andrews et al. (eds), The SAGE Handbook of Digital Dissertations and Theses, London: SAGE Publications, pp. 461-92.

\section{Contributor details}

Mike McAuley has been an educator and researcher in design since the 1990s, teaching both studio- and theory-based courses at a number of universities. He is currently Head of Programs: Bachelor of Design, Bachelor of Design Futures, Bachelor of Design and Business at Griffith University in Queensland. Prior to taking on his recent role he was subject director in Illustration at Massey University's College of Creative Arts in Wellington, New Zealand (1995-2013). He also taught at the University of Newcastle, NSW where he was programme convenor for Visual Communication Design (2014-16). 
Mark Roxburgh is associate professor of design at the University of Newcastle.

Mark’s research interests cover design research, visual communication theory and practice, photographic theory and practice and user experience design. His Ph.D. explored the central role that visual images and visual perception play in design, with a specific emphasis on how photographic images condition us to perceive, experience and transform the world in a self-replicating manner. His ongoing research pursuits have been: developing a phenomenological theory of photography to counter the dominance of critical theory and semiotic deconstruction; developing a theory of design as a form of embodied perceptual synthesis to counter the dominance of the design problem solving metaphor.

Contact:

E-mail: Mike.mcauley@griffth.edu.au

E-mail: mark.roxburgh@newcastle.edu.au

Notes

1 'DESN 1002 Design Contexts 2: When - Histories of Visual Communication Design'.

2 'DESN 1001_Design Contexts: What - Definitions, Theories and Practices of Design'. 